\title{
Cloud Computing: How does it differ from IT outsourcing and what are the implications for practice and research?
}

Ogan M. Yigitbasioglu. Queensland University of Technology. Australia ogan.yigitbasioglu@qut.edu.au

Kim Mackenzie. Queensland University of Technology. Australia k3mackenzie@qut.edu.au

Rouhshi Low. Queensland University of Technology. Australia r.low@qut.edu.au

\begin{abstract}
The purpose of this paper is to provide an evolutionary perspective of cloud computing (CC) by integrating two previously disparate literatures: $\mathrm{CC}$ and information technology outsourcing (ITO). We review the literature and develop a framework that highlights the demand for the CC service, benefits, risks, as well as risk mitigation strategies that are likely to influence the success of the service. CC success in organisations and as a technology overall is a function of (i) the outsourcing decision and supplier selection, (ii) contractual and relational governance, and (iii) industry standards and legal framework. Whereas CC clients have little control over standards and/or the legal framework, they are able to influence other factors to maximize the benefits while limiting the risks. This paper provides guidelines for (potential) cloud computing users with respect to the outsourcing decision, vendor selection, service-level-agreements, and other issues that need to be addressed when opting for $\mathrm{CC}$ services. We contribute to the literature by providing an evolutionary and holistic view of CC that draws on the extensive literature and theory of ITO. We conclude the paper with a number of research paths that future researchers can follow to advance the knowledge in this field.
\end{abstract}

Keywords: cloud computing, information technology (IT) outsourcing, risk mitigation, software as a service (SAAS) 


\section{INTRODUCTION}

Cloud computing (CC) has received much attention in recent years, especially from the business community and the media. Also, the endorsements by a number of governments around the world, namely in the U.S. (The Federal CC Strategy) and in Australia (The Australian Government Cloud Implementation Initiative) have provided fresh impetus for this emerging technology. The merits of $\mathrm{CC}$ are perhaps best epitomized in the U.S. Federal CC Strategy report. Vivek Kundra, the former U.S. Chief Information Officer claimed that CC can save the US Government U\$20 billion annually which made up a quarter of its 2011 IT budget (Kundra, 2011).

Gartner Research estimated the CC industry to reach a \$150 billion by 2014. Forrester Research's forecast was more modest but still impressive, a growth from U $\$ 40.7$ billion in 2011 to $\$ 159.3$ billion in 2020. In addition to forecasts, IBM carried out a survey with more than 3,000 global CIO's and found that $60 \%$ of organizations were "ready to embrace CC over the next five years as a means of growing their businesses and achieving competitive advantage" (IBM, 2011).

Despite the prospects of $\mathrm{CC}$ and the optimistic forecasts, $\mathrm{CC}$ has not proven to be immune to failure. For example, Harris Corporation, a U\$6 billion US communications company closed down its CC facility outside Washington DC in 2012, after less than a year of operation. The reason for this move was that both its government and commercial customers preferred hosting "mission-critical information" on their own premises rather than on the cloud (Garling, 2012).

To date, most research on CC has focused on the technical aspects of this technology (Youseff et al., 2008) while some recent studies have also discussed the business implications of $\mathrm{CC}$ in terms of organizational benefits and risks (e.g. Leimeister et al., 2010, Benlian and Hess, 2011). Although, a substantial number of studies already exist on CC, it is still unclear how or whether CC differs from the traditional but not necessarily successful concept of Information Technology Outsourcing (ITO) (Barthelemy, 2001, Lacity et al., 2009). Much of the research on $\mathrm{CC}$ examined the concept in isolation with little or no reference to the extensive literature on ITO. This might be partly due to the focus on the technicalinstead of the service aspect of the technology. On the other hand, recent studies and textbooks on ITO failed to take notice of CC as a concept overall (Desai, 2009, Aubert et al., 2012, Fitoussi and Gurbaxani, 2012). This is surprising given 
the attention $\mathrm{CC}$ received over the last years. Only a few studies differentiate CC from ITO (e.g. Katzan and Dowling, 2010, Leimeister et al., 2010), although very briefly due to their different focus. It is this gap that we address with this study and identify as a research opportunity. Our aim is to integrate two previously disconnected literatures and to provide an evolutionary and holistic perspective of $\mathrm{CC}$ as an emerging technology and service. Taking this approach, we identify and focus on the potential benefits, risks, and mitigation strategies to increase the likelihood of ITO success. We conclude the paper with the implications of cloud computing on practice and research from the business and accounting perspectives.

\section{CLOUD COMPUTING DEFINED}

The term CC represents a complex interplay of IT related capabilities that have evolved to represent one of the major developments in the history of computing, as it has fundamentally changed the way in which IT services are invented, developed, scaled, updated, maintained and financed (Marston et al., 2011). Owing to the complexity of $\mathrm{CC}$, defining it in its entirety is equally challenging. Leimeister et al. (2010) define CC as "an IT deployment model, based on virtualization, where resources, in terms of infrastructure, applications and data are deployed via the internet as a distributed service by one or several service providers....services are scalable on demand and can be priced on a pay-per-use basis". Marston et al. (2011, p. 177) provide a definition from a business perspective that encompasses key benefits for business as well as its technological features, i.e. IT services "are delivered on-demand to customers over a network in a self-service fashion, independent of device and location....users pay for the service as an operating expense without incurring any significant initial capital expenditure, with the cloud services employing a metering system..." These definitions reflect that $\mathrm{CC}$ as a technology and service emphasises remote delivery of IT related technical and application resources for an organisation. It is noteworthy that none of these definitions make a reference to "outsourcing". We feel that it is important to define $\mathrm{CC}$ in terms of outsourcing to avoid any misconception. Thus we define $\mathrm{CC}$ as an enabler of ITO whereby access to IT resources such as software, hardware, and platform are delivered over the Internet as a service and users are predominantly charged on a pay per-use basis. 
The CC technology is delivered through three layers, namely Software as a Service (SAAS), Platform as a Service (PAAS), and Infrastructure as a Service (IAAS). These layers are based on both, old and new computing concepts such as Service Oriented Architectures (SOA), distributed and grid computing, as well as virtualization (Youseff et al., 2008). CC adopters can choose among one or several of the services offered. With the SAAS model, clients run applications such as Facebook and Twitter on the cloud as opposed to running them on local computers (Marston et al., 2011). An example of an accounting software package that is now available as a SAAS model is Mind Your Own Business (MYOB) which no longer needs to be purchased and downloaded onto a PC as stand-alone software (Timson, 2010). A PAAS model facilitates the development and deployment of applications, eliminating the need to manage and maintain costly hardware and software layers (Marston et al., 2011). Examples of PAAS include Microsoft's Azure Services Platform and Salesforce's Force.com. With the IAAS model, only storage and computing capabilities are offered as a service but the management of the operating system or the applications are not supported. Amazon's Cloud Formation and Google's Compute Engine are among the examples of commercially successful IAAS.

\section{CLOUD COMPUTING AS AN EVOLUTION OF ITO}

Cloud computing is an outsourcing decision as it gives organizations the opportunity to externalize and purchase IT resources and capabilities from another organisation as a service. Hence the (IT-) outsourcing literature and theory can provide the much needed insight for the understanding of the economics of the concept. Transaction cost economics (TCE) and the resource-based view of the firm provide valuable but distinct theoretical frameworks with respect to the outsourcing decision of the firm. Whereas economic costs underlie TCE, the resource-based of the firm focuses on strategic imperatives. TCE argues that vertical integration should be the last resort not the first as a form of exchange and that the market is often the most efficient institutional arrangement (Williamson, 1991). However, when transactions (costs) become too complex (high) or involve assets that are more worth within the specific relationship (asset specificity), then firms would chose vertical integration over outsourcing. ITO exposes the organization to a number of risks that have a direct impact on transaction costs. A number of studies have used TCE as the underlying theory for analysing ITO (e.g. 
Aubert et al., 2012). We explain the risks in the next section, which are also summarized in Table 1.

The resource based view of the firm sees outsourcing as an opportunity to acquire and allocate valuable IT resources. However, if certain IT resources and activities are considered strategic then these resources are less likely to be outsourced (Goles and Chin, 2005). There is some evidence for this theory in the ITO literature. For example, Beaumont and Costa (2002) report that $42 \%$ of the respondents of an Australian survey outsourced application development and maintenance but only for a small portion of core applications. Other highly likely outsourced IT functions are telecommunication management, systems integration, and systems operation (Beaumont and Costa, 2002, Teng et al., 2007) which is consistent with the selective outsourcing trend (e.g. Earl, 1989, Willcocks et al., 1995) suggesting that organizations outsource "mundane aspects of a function such as a call centre, but to develop in house and keep secret those aspects that give competitive advantage and/or contribute to the company's public image" (Beaumont et al. 2002, p. 20).

Outsourcing involves arms lengths or long distance purchases of services, principally, but not necessarily, via electronic mediums such as the telephone, fax and the Internet (Bhagwati et al., 2004). Outsourcing isn't limited to a particular business process or capability and may involve accounting (e.g. bookkeeping and investment advice) and IT. IT is outsourced when part or all of the IT function is subcontracted to a vendor. Outsourcing is a legal agreement between firms, administered by a contract (Goles and Chin, 2005). Thus, the success of ITO depends on the terms of the contract (price, flexibility etc.) but also how well the relationship with the vendor is managed, which becomes critical given the notion of incomplete contracts (Hart and Moore, 1988).

We define success as the perceived effectiveness of the outsourcing relationship and the overall satisfaction with the contract (Saunders et al., 1997). Satisfaction is also a good predictor of the intention to continue with the contract, as well as the likelihood to repurchase the service in the future (Koh et al., 2004, Poppo and Lacity, 2006). ITO can be considered a success when initial expectations with respect to for example, financial considerations or technical capabilities are largely met through the outsourced service. Conversely, ITO could be considered a failure when for example, additional costs which were initially 
unaccounted for eat away a significant portion of the expected savings (Barthelemy, 2001).

The relevant literature provides a number of reasons why IT is outsourced: (i) cost cutting, (ii) focus on core competencies, (iii) business process improvement initiatives, (iv) the need to access expertise, skills, and technology, (v) flexibility, (vi) scalability and even (vii) political factors (Lacity et al., 2009). The primary motivation for outsourcing by large firms may be to cut costs, whereas smaller firms outsource to minimise IT capital investment and business risk of noncompetitiveness. Nevertheless both large and small firms use outsourcing as a means for managing work overloads in the peak activity periods (Cooper, 2006). However, there is mixed evidence in terms of the financial benefits obtained from outsourcing (Lacity et al. 2009; Barthelemy, 2001). Whereas some studies report on improvements in the client-firm's financial performance (e.g. Mojsilovic et al., 2007), others found either a deterioration (e.g. Wang et al., 2008) or insignificant change in performance (e.g. Bhalla et al., 2008). ITO fails because companies do not factor in all the costs involved with the outsourcing process (Barthelemy, 2001). Often "hidden costs" partially or entirely eat away expected benefits of ITO. Barthelemy (2001) identifies four types of hidden costs: (i) vendor search and contracting costs, (ii) initial transition costs, (iii) costs associated with managing the outsourcing effort, and finally (iv) post-IT transition costs.

Researchers have different views on how CC differs from ITO. Katzan and Dowling (2010, p. 29) note that "with outsourcing an existing function is moved out of the department, enterprise, or geographic jurisdiction, whereas with CC the home of an application originates in the cloud". We are in the view that both CC and ITO may entail the movement of resources from in-house to an external provider. Leimeister et al. (2010) explain the difference between ITO and CC in terms of how the value chain has been transformed through the emergence of online services and new actors (e.g. service providers and brokers) in to a "value network". They argue that the existence of new actors leads to complex relationships and hence a myriad of outsourcing possibilities and combinations that was previously more restricted (Leimeister et al. 2010). Another difference between the traditional ITO and CC is the length of the contract. CC contracts often have shorter life-cycles than traditional ITO contracts, which can be monthly, weekly, daily or even hourly. Thus, CC seems to offer more flexibility 
and less commitment on the part of the client. Finally, with CC, users can (near) instantly scale up or down the level of services or request new services since computing resources are managed through software (Marston et al., 2011). This is further explored in Section 3 which discusses the benefits and risks of CC from the accounting and performance perspectives.

\subsection{Cloud computing benefits and risks}

CC offers many advantages that surpass the promises of traditional ITO. These are: easy scalability (Marston et al., 2011), access to new software (Marston et al., 2011), and reliability (Yoo, 2011). Given that servers and desktop computers have an average capacity utilization of less than $30 \%$ and $5 \%$ respectively, a service model for IT might lead to significant cost savings.

$\mathrm{CC}$ allows near instant pay-per-use access to software and hardware that would otherwise require significant upfront capital outlays. Thus, $\mathrm{CC}$ can provide access to advanced capabilities such as predictive analytics that would otherwise be difficult to attain, especially by SME's as they often lack the resources. The possibilities are vast and aside from financial considerations, clients would only be limited by the diversity of services offered by vendors. Hence, CC providers that offer cutting-edge technology with an ability to anticipate future requirements are more likely to succeed in the market. For example, a technology that may be of interest to organizations is continuous auditing (CA) (Vasarhelyi and Halper, 1991). CA allows the monitoring of transactions on an ongoing basis so as to alert users of potentially fraudulent activities. CC providers would be in a good position to host this capability for clients that already have their financial data in the cloud. This has the potential to remove barriers to entry and innovation as far as computing is concerned, giving SME's a better chance to compete globally (Marston et al., 2011). Reliability is said to improve because it is assumed that the CC service provider (CSP) would develop expertise in managing, running, and maintaining IT resources.

Not only does the case for the CC business model emphasise enormous cost savings in relation to IT hardware, software, and IT related personnel expenditure, but the changes associated with how it is accounted for on paper may also reflect a substantial increase in profits. Historically, accounting norms have treated IT as a capital expense owing to the initial investment outlay required for hardware and software resources. This is referred to as the "Cap-ex" model. However, 
outsourcing IT services to an external provider enables it to be accounted for as an operational expense, referred to as the 'Op-ex' model (Marston et al. 2011). From a financial reporting perspective, this can significantly adjust the value of company assets and hence profit status.

The example of the 2011 initiative between Google and the accounting software package MYOB helps to illustrate the benefits of the SAAS delivery model. In an attempt to encourage more Australian small businesses to develop an online presence and take advantage of new CC initiatives, Google and MYOB announced that they would provide free websites and domain names for 50,000 Australian small businesses. Titled "Getting Aussie Business Online”, the bold venture would provide the free resources for a one year period before charging a $\$ 5$ fee per month from the second year onwards. The basic website presence would be designed for eventual integration with cloud based software tools such as MYOB Live Accounts, creating a more streamlined approach to managing ecommerce processes online. Using this approach, rather than work off two IT systems (online and internal), small businesses can use one set of data that will enable them to purchase online, "check inventory levels, check the status of an order, and allow a customer to come in under a password-protected site and download an invoice" (Khoo, 2011, p. 1). The example also provides an excellent example of the risks associated with $\mathrm{CC}$, where many small businesses could be easily persuaded by the attractive offer and having limited understanding of the risks involved, particularly from an accounting perspective. These risks are discussed in detail below.

Many CC risks are directly applicable from the ITO literature. The number of risks identified in the (IT) outsourcing literature is overwhelming (with more than 40 according to a study by Lacity et al., 2009). One of the risks relates to business continuity. Non-interrupted availability of $\mathrm{CC}$ services and reliability has been touted as the key selling point for $\mathrm{CC}$. However, because $\mathrm{CC}$ relies on the Internet, connectivity problems could lead to service disruptions. This could be the Internet third party (ISP) provider or the cloud service provider experiencing connectivity problems, rendering the service unavailable. For example, in March 2009, Microsoft Windows Azure was down for 22 hours (Hoover, 2009). More recently in April 2011, a large scale outage hit Amazon, affecting Amazon's Web Services' Elastic Compute Cloud (EC2). The outage took out popular social 
networking services Foursquare, FormSpring, Heroku, HootSuite, Quora and Reddit (Winteford, 2011). These outages prevent users from accessing applications or data stored in the cloud and the financial cost of these outages can be quite high especially when mission critical- such as accounting information systems are outsourced.

A second risk is interoperability, where clients may find themselves locked in to a specific cloud provider, unable to transition from one provider to another, or finding a lack of interoperability between their existing in-house infrastructure and cloud based services (Martin, 2011, Soma et al., 2011). This issue arises due to a lack of standard data formats and application platforms governing CC (Vincent and Hart, 2011).

A further difficulty with $\mathrm{CC}$ relates to auditability of data. This is particularly pertinent for businesses which hold data and are required by law to provide assurances regarding their computing environments to their customers or regulators or who are required to perform audits on the data held (Soma et al., 2011). This is not an issue where the data is stored on the businesses' own servers because the business can control its own in-house computing facilities. But in the cloud environment, data is outsourced to the cloud provider, causing the business to lose control over that data. The cloud provider's terms of use agreement may prohibit technical procedures a user would like to perform in order to test system vulnerability or system performance (Martin, 2011). Service level agreements may also not require the cloud provider to undertake that testing. This means there could be security gaps for the user (Martin, 2011). In any event by entrusting data to the cloud service provider to perform backups and other maintenance, the user has no control over the procedures if any taken by the cloud provider and the quality of procedures undertaken (Murdoch, 2010, Soma et al., 2011).

Finally, the biggest concern in relation to migrating to the cloud is the integrity, privacy and, security of data outsourced to the cloud (e.g. Lanois, 2010, Martin, 2011, Soma et al., 2011, Vincent and Hart, 2011). Traditional subcontracting and outsourcing also attracted privacy and security issues. The difference is that where data that is stored on the client's servers, the client retains control over the security of the servers. But where client data is given to the cloud provider to store, it is stored by the cloud provider in multiple data centres across multiple jurisdictions (Griffith, 2012). Google, for example, has data centres in the US, 
Europe, Russia, South America and across Asia (Griffith, 2012). Whilst storage across multiple locations may distribute the risk of a single point of failure, it also creates multiple possible points for intrusion. The possibility has also been raised that cloud providers may not accurately report to their clients about the data stored on the cloud, that cloud service providers may hide data breaches or loss of data stored on the cloud to protect their reputation (Wang et al., 2010). Thus one of the biggest concerns with $\mathrm{CC}$ is the uncertainty with regards to how cloud providers will ensure the security, privacy, integrity and confidentiality of data stored in the cloud (Martin, 2011). Concerns regarding security, privacy and integrity of data are further exacerbated by little and/or inconsistent regulatory framework regarding the privacy and security of data (Soma et al., 2011). As noted by Griffith (2012), in some countries laws give government agencies a right to inspect data held there and privacy law safeguards are unknown.

Owing to the importance of security in cloud services, providers are taking great lengths to ensure business confidence and trust, by securing their systems against insider attacks by protecting and restricting access to physical resources, and through the adoption of "stringent accountability and auditing procedures" (Gurav and Shaikh, 2010, p. 227). However, as insiders still retain the ability to access customer information, combined with the lack of technical solutions that guarantee the "confidentiality and integrity of computation" (Gurav and Shaikh, 2010, p. 227), the risks involved for business organisations is of great concern.

The contractual agreements governing the various parties from the cloud provider to subcontractors to the cloud user may also complicate matters (Martin, 2011). Who would be liable should data be lost or compromised? Reliance on the contract for managing risk is problematic as it is unable to "completely cover and specify the complexity of an outsourcing project" owing to the IT subject matter of the contract being "a very volatile, fast changing asset" (Leimeister et al. 2010, p. 6).

These risks have forced some businesses to reconsider their move to the cloud, despite its many benefits as demonstrated in The Harris Corporation case. Section 4 discusses in detail the implications of $\mathrm{CC}$ for businesses and examines how the risks identified in this section could be managed. 


\section{IMPLICATIONS FOR PRACTITIONERS}

There appears to be many benefits of $\mathrm{CC}$ which we classify along four dimensions: a) financial, b) strategic, c) technical, and d) legal/transaction (see Table 1). However, many of the benefits do also come with some risks so it is vital that $\mathrm{CC}$ adopters effectively address them. Table 1 gives a summary of the corresponding risk mitigation strategies that are to a large extent derived from the ITO literature. We briefly explain them next.

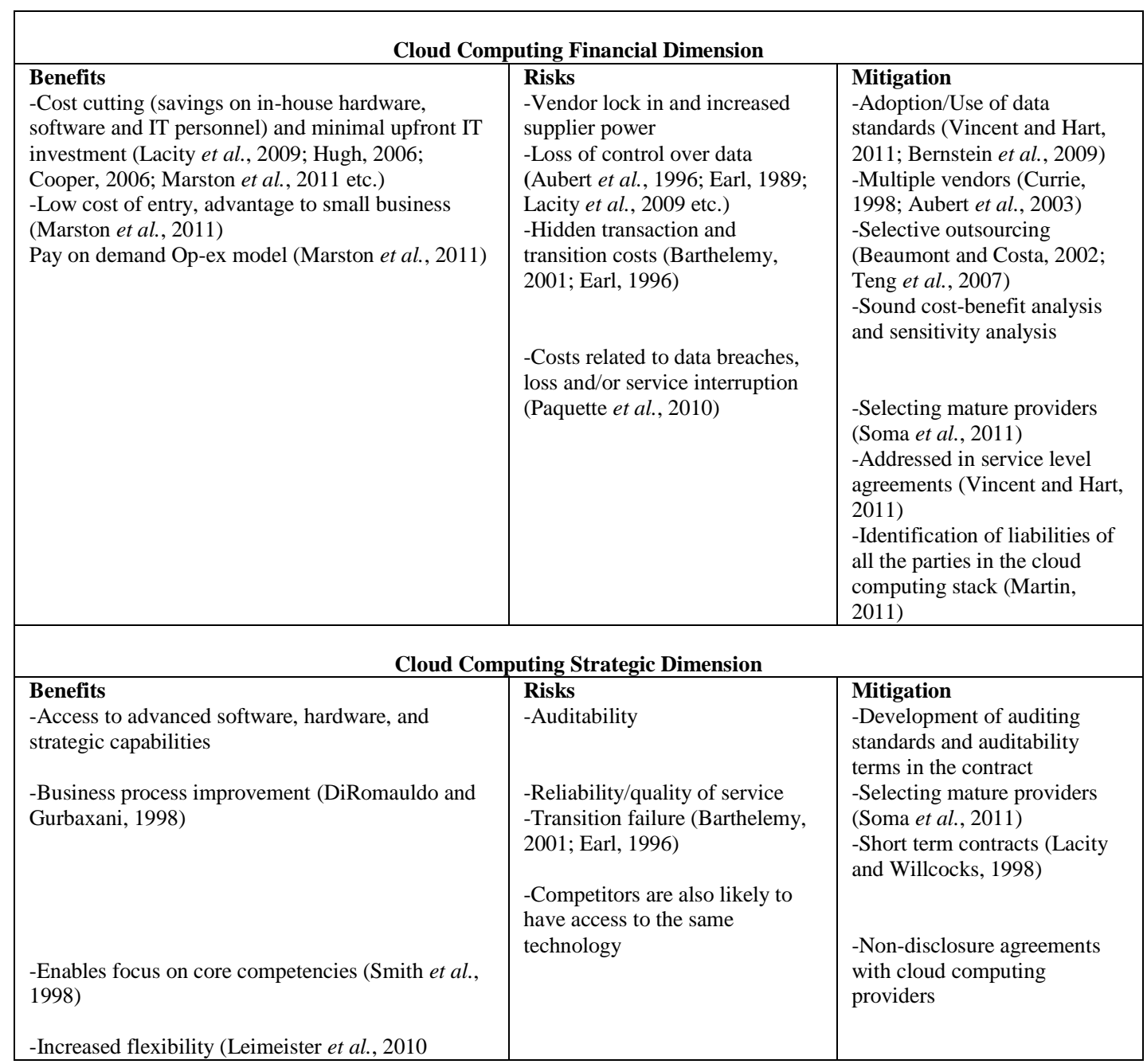

Table 1: Cloud computing Risks and Mitigation Strategies 


\begin{tabular}{|c|c|c|}
\hline \multicolumn{3}{|c|}{ Cloud Computing Technical Dimension } \\
\hline $\begin{array}{l}\text {-Increased reliability as } \\
\text { accessing best expertise in } \\
\text { field } \\
\text {-Transition from legacy } \\
\text { systems } \\
\text {-Instant scalability (Leimeister } \\
\text { et al., 2010; Marston } \text { et al., } \\
\text { 2011) }\end{array}$ & $\begin{array}{l}\text { Risks } \\
\text {-Poor supplier capability/service } \\
\text {-Auditability } \\
\text { Inability to examine quality of vendor } \\
\text { services (Soma et al., 2011; - } \\
\text { Murdoch 2010; Soma } \text { et al., 2011) } \\
\text {-Security/privacy breach } \\
\text {-Data theft, integrity, privacy and } \\
\text { confidentiality } \\
\text { (Aubert } \text { et al., 2003) } \\
\text {-Internet risks } \\
\text {-Non reporting of data security } \\
\text { breaches (Vincent and Hart, 2010; } \\
\text { Martin, 2011; } \\
\text { Lanois, 2010; Soma et al., 2011; } \\
\text { Wang et al., 2010) } \\
\text {-Service provider or third party } \\
\text { related disruptions } \\
\text {-Interoperability and lack of data and } \\
\text { platform standards } \\
\text {-Data storage complexity }\end{array}$ & $\begin{array}{l}\text {-Compliance with security standards, security } \\
\text { seals, identification of protocols to be followed } \\
\text { in the event of breach in contract } \\
\text {-Disaster recovery plan (Soma et al., 2011) } \\
\text {-Data to be kept in agreed locations/legislations } \\
\text { (Marston et al., 2011) } \\
\text {-Addressed in service level agreements } \\
\text { (Vincent and Hart, 2011) } \\
\text {-Liabilities of other parties in the cloud } \\
\text { computing stack (Martin, 2011) }\end{array}$ \\
\hline \multicolumn{3}{|c|}{ Cloud Computing Legal Dimension } \\
\hline $\begin{array}{l}\text { Benefits } \\
\text {-Short term contracts (hourly, } \\
\text { weekly, monthly): flexibility }\end{array}$ & $\begin{array}{l}\text { Risks } \\
\text {-Inflexible contracts } \\
\text {-Breach of contract } \\
\text { (Aubert } \text { et al., 1996) } \\
\text { (Aubert } \text { et al., 2003) Gurav and } \\
\text { Shaikh 2010) } \\
\text {-Insolvency, End of contract } \\
\text {-Inconsistent regulatory frameworks } \\
\text { and privacy laws } \\
\text {-Jurisdiction of data storage and } \\
\text { server location issues } \\
\text {-Third party access to data (Vicent } \\
\text { and Hart, 2011; Martin, 2011; } \\
\text { Griffith 2012; Leimeister } \text { et al., 2010) } \\
\text { Transparency of } \\
\text { Jurisdiction (Murdoch, 2010) }\end{array}$ & -Addressed in contract terms \\
\hline
\end{tabular}

Table 1: Cloud computing Risks and Mitigation Strategies (continued).

Vendor lock-in is a situation that should be avoided as it increases the bargaining power of the vendor and can therefore lead to higher service costs. Engaging multiple suppliers, signing short term contracts (Lacity and Willcocks, 1998) and outsourcing standard IT services for which there are many suppliers (Lacity and Hirschheim, 1993, De Looff, 1995, Apte et al., 1997) are effective strategies that can minimize this risk. To prevent lock-ins, businesses should consider questions such as - does the cloud provider's service level agreement 
prevent data given to the cloud provider to be extracted at a later date; if the business changes cloud providers, can data be migrated to the new cloud provider? Also, does the vendor adhere to common data standards? (Vincent and Hart, 2011). Close examination of service level agreements is therefore vital in this regard. Larger businesses may find that they have a stronger influence in negotiating contracts that are suitable for them. Smaller businesses may have less bargaining power. For these businesses, comparison between various cloud providers and their contractual agreements would be important (Vincent and Hart, 2011).

The security risks are particularly concerning in relation to financial and accounting related data stored in the cloud, and the ability to detect and prevent acts of fraudulent activity or misconduct. From an ASX reporting obligation perspective, listed corporations that migrate operational and data management services to the cloud without informing shareholders may breach public accountability legal requirements (Marston et al. 2011). Given the lack of consistent regulatory framework over data stored in the cloud, it would seem that for now, the contract governing the parties is of critical importance. Thus the implication for businesses is to examine closely service legal agreements before signing up with the cloud provider.

To establish trust in the vendors' service, clients could also request an independent audit of the service. For example, SysTrust, a certification developed by the American Institute of Certified Public Accountants and Canadian Institute of Chartered Accountants to measure system reliability is known to positively affect the intention to use an online accounting system (Greenberg and Li, 2012). Furthermore, more mature providers might be capable of providing greater protection than less mature providers as less mature providers may not have evolved their processes sufficiently to provide rapid and reliable recoveries (Soma, 2011). Both client and supplier capabilities are equally important since failure cannot be avoided if, for example, the supplier is incompetent no matter how well the relationship is formally and informally managed. Capabilities identified relate to, among others, the clients' IS technical maturity (e.g. position in the Capability Maturity Model), human resources management, supplier management, contract negotiation, domain capability, and change management (Lacity et al., 2009). 
Research on ITO critical success factors (CSF) may also provide valuable directions for CC clients. CSF's relate to the effectiveness of three processes: (i) the ITO decision, (ii) contractual governance, (iii) and relational governance (Lacity et al., 2009). With respect to the decision, the extent of outsourcing (less is better), top management support, the criticality of the outsourced service, and vendor evaluation play an important role in the outsourcing success (Lacity et al., 2009). Some of these success factors are in line with the literature that looks at other technology adoption such as studies on Enterprise Resource Planning Software (Finney and Corbett, 2007) or information systems in general (RaguNathan et al., 2004). As for the contracts, level of detail, duration, and the size of the contract all are positively related to success. Organizations that outsource their IT must successfully manage their relationships with suppliers. Relational governance is facilitated and enhanced through factors such as trust (in its variety of forms, e.g. calculus-based trust, knowledge-based trust), norms, mutual dependency, open communication, and sharing of information.

Finally, pilot tests to get used to working with suppliers can also help minimize the risk of outsourcing (Lacity et al, 1998). This would suggest that clients it might be less risky to outsource non-core applications first and then to move on to more critical applications if the level of service is satisfactory.

Figure 1, a proposed framework for the success of ITO through CC illustrates the concepts discussed in this study. According to the framework, ITO success is mediated by the effective utilization of risk mitigation techniques. The framework can also be used for informing future research, which is further explored in Section 5 .

\section{DIRECTIONS FOR FURTHER RESEARCH}

With the exception of Benlian and Hess (2011), studies on CC have had a technical and/or non-empirical approach. Hence, $\mathrm{CC}$ as a field presents a large research potential. We think case studies on $\mathrm{CC}$ experiences could especially be valuable. We identified a number of research directions for the future that are also captured in Figure 1. With this framework, we also highlight and group three risk mitigation areas that are likely to influence the success of $\mathrm{CC}$ adoption. We included "industry standards and legal framework" as a third dimension despite the fact that organizations at the individual level will have little control over its development. Nevertheless, they may be in a position to demand vendor 
certifications (e.g. PCI DSS, SysTrust), as well as the storage of data only in jurisdictions that are sufficiently 'mature'.

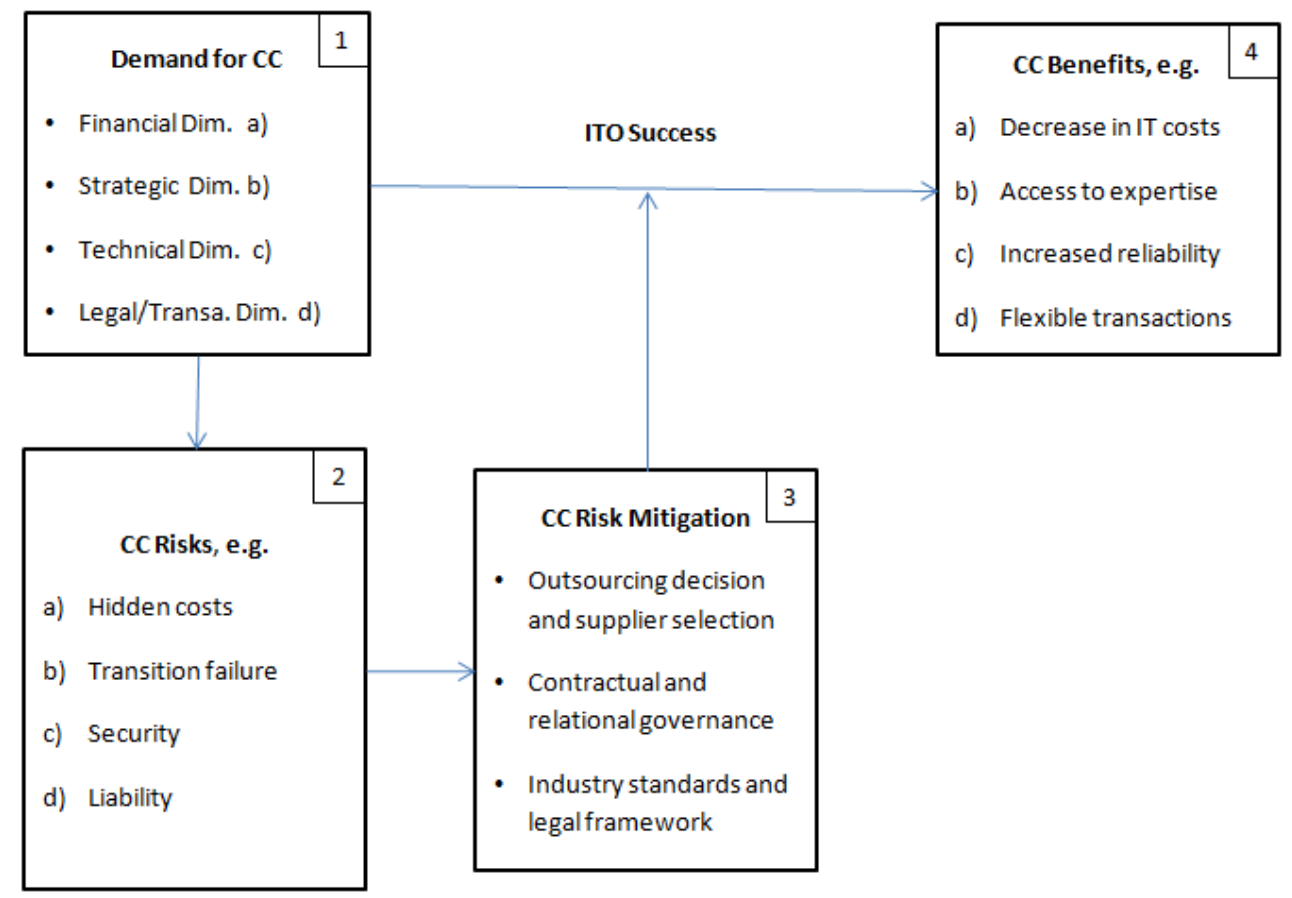

Figure 1: Framework for the success of IT Outsourcing through CC

\subsection{Demand for $\mathrm{CC}$}

The first research path relates to the demand for CC services (Box 1). It is generally argued that ITO is driven by cost saving motives rather than strategic factors (Lacity et al., 2009). Is this also true for CC? Access to cutting edge technology and applications might lead to strategic advantage. With CC, companies can tap into the expertise of innovative IT companies such as SAP to remain at the forefront of technology. Evidence from a sample of German companies using SAAS gives some support for this view, although perceived cost benefits still seem to be stronger (Benlian and Hess, 2011). The benefits are likely to depend on the type of applications outsourced, i.e. core or non-core. Accounting applications are vital to a business and could be considered core. So, the question remains whether companies will take the risk and outsource core applications or will we see more cases of CC failures? Research could identify the drivers of $\mathrm{CC}$ across different countries and compare them to the drivers in the 
ITO literature to see whether strategic incentives have replaced cost considerations. Furthermore what kinds of applications are moved into the cloud, i.e. core or non-core and what new services/technologies are demanded by CC customers?

Furthermore, what will happen to the legacy applications such as Enterprise Resource Planning Systems that the companies have been investing in and maintaining over the many years? Many applications are highly customised, tailored to addressing the unique business processes and environments of companies. Can CC service providers match these solutions? Because of this, we posit that the transition to $\mathrm{CC}$ is likely to be slow for established companies with custom legacy systems. On the other hand, new start-ups are likely to find CC very attractive. Perhaps additional research can be conducted to see if there are differences in uptake between established businesses and start-ups or SME's and how cloud providers might alter their offerings to attract established businesses.

\subsection{CC benefits}

Another stream of research could look at the benefits of CC such as its financial impact on the adopting firm (Box 4). One approach followed by researchers in the technology adoption literature is the stock market reaction to technology adoption announcements (Hunton et al., 2002, Jeong and Stylianou, 2010). Event studies that look at CC adoption announcements and market reaction would measure the perceived value of such services. Here, service providers' image or reputation is likely to have an influence on the direction and magnitude of the reaction although the type of services or technology outsourced (e.g. core vs. non-core) will play a role too.

An alternative path to follow would be the association between $\mathrm{CC}$ adoption and financial performance measures. This path was followed by many technology focused researchers in the context of ERPS (e.g. Poston and Grabski, 2000, Hunton et al., 2003, Nicolaou, 2004, Nicolaou and Bhattacharya, 2006) and ITO (Mojsilovic et al., 2007). However, even if a large portion of IT is outsourced, given the small proportion of IT spending in relation to other costs, its effect on firm-level financial measures such as profitability will be difficult to detect (Aubert et al., 2008). Thus, process based measures such as improved cycle times and quality in reporting as followed in subsequent ERPS (e.g.Velcu, 2007) or ITO (e.g. Wang et al., 2008) studies may be a better way to go forward. 


\subsection{CC risks and mitigation}

Research could also be directed at the risks and risk mitigation strategies/techniques associated with CC (Boxes 2 and 3), particularly examining the risks associated with security and privacy of information stored on the cloud. This research could examine the various laws and regulations governing security and privacy across multiple jurisdictions and discern from these laws common themes impacting on businesses migrating to the cloud. For example, identifying jurisdictions that lack appropriate regulation governing security and privacy and jurisdictions with strong regulations. In those jurisdictions with strong regulations, how do these regulations impact on data stored on the cloud? Businesses thinking of migrating to the cloud could examine where the data servers of potential cloud providers are located so as to be able to judge the level of regulatory impact on their business. Further research could also be conducted on the impact of cloud providers' contractual provisions on security and privacy issues. As noted in the section above on benefits and risks, contractual agreements between the cloud provider and the cloud user can present difficulties. Cloud providers could insert clauses giving the cloud provider the right to look at the person's private files as well as to reuse the information in them as in the case of Google Drive (Griffith, 2012). How do these contracts impact on businesses migrating to the cloud? Could research identify common pitfalls that businesses should be wary of when examining these contracts or service level agreements? With regards to disparaging standards and protocols between cloud providers causing the 'lock-in' issue, research could look into the development of inter-cloud standards and protocols.

\section{CONCLUSION}

ITO traditionally emphasised the relationship aspect with the service vendor, which explains how the management of that relationship was considered critical to its success. In contrast, the literature on $\mathrm{CC}$ seems to focus more on the technology aspect of the service. This shifts the notion of cloud services from being a human centred activity as in traditional ITO services, to a more remote and anonymous technology connected network within which to seek opportunity to increase business value. Thus access to the Internet could be considered the primary requirement for taking advantage of the ever increasing complex array of cloud services, rather than building long term relations with providers. This 
differentiation may further explain how the CC industry has successfully thrived as beneficiaries from this shift of trust from the vendor to the Internet itself, whereby organisations are willing to risk migrating data and information into cloud solutions offered by Internet giant providers, despite the increased vulnerabilities this represents. However, despite the depersonalisation of the client/vendor service model, organisations still rely on the legal contract as the primary means for ensuring that a high quality, secure service is provided, despite the lack of global regulatory standards and service provider issues.

From a financial benefits perspective, it appears that cost savings remain an important driver of cloud services (including the shift to the Op-ex model), however, the increased capabilities afforded by new software innovations and technical capability are also attracting customers for cloud services, especially small businesses. Therefore, where initially the use of ITO was emphasised for the low cost supply of non-core services, it could be argued that cloud services now emphasise the provision of new types of service capabilities that may increase the value proposition of an organisation.

The development of the Internet over the past two decades has dramatically increased the ability to provide quality flexible IT services online in a myriad of complex combinations. At the same time, however, adequate controls relating to increased data security, integrity, transparency and auditability vulnerabilities are yet to be surmounted. Many of the risks can be addressed by using good contracting practices, although given the notion of incomplete contracts, relational governance is likely to remain an important factor especially when businesses outsource mission critical resources. We discussed the risk mitigation techniques available to organizations as well as future research directions in this field.

\section{REFERENCES}

APTE, U. M.; SOBOL, M. G.; HANAOKA, S.; SHIMADA, T.; SAARINEN, T.; SALMELA, T. \& VEPSALAINEN, A. P. J. (1997): "IS outsourcing practices in the USA, Japan and Finland: a comparative study", Journal of Information Technology, vol. 12: 289-304. http://dx.doi.org/10.1080/026839697345017

AUBERT, B. A.; BEAURIVAGE, G.; CROTEAU, A. M. \& RIVARD, S. (2008): "Firm strategic profile and IT outsourcing". Information Systems Frontiers, vol. 10: 129-143. http://dx.doi.org/10.1007/s10796-008-9065-8 
AUBERT, B. A.; HOUDE, J. F.; PATRY, M. \& RIVARD, S. (2012). "A multilevel investigation of information technology outsourcing", The Journal of Strategic Information Systems. http://dx.doi.org/10.1016/j.jsis.2012.04.004

BARTHELEMY, J. (2001). The hidden costs of IT outsourcing. Mit Sloan Management Review, vol. 42: 60-69.

BEAUMONT, N. \& COSTA, C. (2002): "Information technology outsourcing in Australia", Information Resources Management Journal (IRMJ), vol. 15: 14-31. http://dx.doi.org/10.4018/irmj.2002070102

BENLIAN, A. \& HESS, T. (2011): "Opportunities and risks of software-as-aservice: Findings from a survey of IT executives", Decision Support Systems, vol. 52: 232-246. http://dx.doi.org/10.1016/j.dss.2011.07.007

BHAGWATI, J.; PANAGARIYA, A. \& SRINIVASAN, T. N. (2004): "The muddles over outsourcing", The Journal of Economic Perspectives, vol. 18, 93114. http://dx.doi.org/10.1257/0895330042632753

BHALLA, A.; SODHI, M. S. \& SON, B. G. (2008): "Is more IT offshoring better? An exploratory study of western companies offshoring to South East Asia", Journal of Operations Management, vol. 26, 322-335. http://dx.doi.org/10.1016/j.jom.2007.02.005

COOPER, C. (2006): "The True Cost of Outsourcing". Charter.

DE LOOFF, L. A. (1995): "Information systems outsourcing decision making: a framework organizational theories and case studies", Journal of Information Technology, vol. 10: 281-297.

DESAI, J. (2009). IT Outsourcing Contracts: A Legal and Practical Guide, ITGP.

EARL, M. J. (1989): Management Strategies for Information Technology, Prentice-Hall. Edwards.

FINNEY, S. \& CORBETT, M. (2007): "ERP implementation: a compilation and analysis of critical success factors", Business Process Management Journal, vol. 13: 329-347. http://dx.doi.org/10.1108/14637150710752272

FITOUSSI, D. \& GURBAXANI, V. (2012): "IT outsourcing contracts and performance measurement", Information Systems Research, vol. 23: 129-143. http://dx.doi.org/10.1287/isre.1100.0310 
GARLING, C. (2012): Cloud' Data Center Closes Because Federal Agencies Prefer Earth. Available: http://www.wired.com/wiredenterprise/2012/02/harris/ [Accessed 4/11/2012].

GOLES, T. \& CHIN, W. W. (2005): "Information systems outsourcing relationship factors: detailed conceptualization and initial evidence". ACM SIGMIS Database, vol. 36: 47-67. http://dx.doi.org/10.1145/1104004.1104009

GREENBERG, R. \& LI, W. (2012): "The Effect of Trust in System Reliability on the Intention to Adopt Online Accounting Systems", International Journal of Accounting and Information Management, vol. 20: 5-5. http://dx.doi.org/10.1108/ $\underline{18347641211272740}$

GRIFFITH, C. (2012): "Australian IT Convenience has its costs as privacy and fee concerns cloud online storage", The Weekend Australian [Online]. Available: http://bit.ly/K3L48k [Accessed 2/11/2010].

GURAV, U. \& SHAIKH, R. (2010): "Virtualization: a key feature of cloud computing", Proceedings of the International Conference and Workshop on Emerging Trends in Technology, ACM: 227-229.

HART, O. \& MOORE, J. (1988): "Incomplete contracts and renegotiation", Econometrica: Journal of the Econometric Society: 755-785. http://dx.doi.org/10. $\underline{2307 / 1912698}$

HOOVER, N. (2009): "Windows Azure Goes Down", InformationWeek [Online]. Available: http://ubm.io/1eBRU9K [Accessed 10/5//2012].

HUNTON, J. E.; LIPPINCOTT, B. \& RECK, J. L. (2003): "Enterprise resource planning systems: comparing firm performance of adopters and nonadopters", International Journal of Accounting Information Systems, vol. 4: 165-184. http://dx.doi.org/10.1016/S1467-0895(03)00008-3

HUNTON, J. E.; MCEWEN, R. A. \& WIER, B. (2002): "The reaction of financial analysts to enterprise resource planning (ERP) implementation plans", Journal of Information Systems, vol. 16: 31-40. http://dx.doi.org/10.2308/jis.2002.16.1.31

IBM. (2011). New Global IBM Study Confirms Cloud Computing Poised to Take Off at Companies. Available: http://ibm.co/lZtfqe [Accessed 3/11/2012]. 
JEONG, B. K. \& STYLIANOU, A. C. (2010): "Market reaction to application service provider (ASP) adoption: An empirical investigation". Information \& Management, vol. 47: 176-187. http://dx.doi.org/10.1016/j.im.2010.01.007

KATZAN, H. \& DOWLING, W. A. (2010): "Software-As-A-Service Economics" Review of Business Information Systems, vol. 14. http://dx.doi.org/10.1287/serv.1. $\underline{4.256}$

KHOO, V. (2011): "Google and MYOB announce free websites and domain names for 50,000 small businesses". Available: [Accessed 25/10/2012].

KOH, C.; ANG, S. \& STRAUB, D. W. (2004): "IT outsourcing success: a psychological contract perspective", Information Systems Research, vol. 15: 356373. http://dx.doi.org/10.1287/isre.1040.0035

KUNDRA, V. (2011): Federal cloud computing strategy, White House, Chief Information Officers Council.

LACITY, M. C. \& HIRSCHHEIM, R. A. (1993): Information Systems Outsourcing; Myths, Metaphors, and Realities, John Wiley \& Sons, Inc.

LACITY, M. C.; KHAN, S. A. \& WILLCOCKS, L. P. (2009): A review of the IT outsourcing literature: Insights for practice, Journal of Strategic Information Systems, vol. 18: 130-146. http://dx.doi.org/10.1016/j.jsis.2009.06.002

LACITY, M. C. \& WILLCOCKS, L. P. (1998): "An empirical investigation of information technology sourcing practices: Lessons from experience", MIS quarterly: 363-408. http://dx.doi.org/10.2307/249670

LANOIS, P. (2010): "Caught in the clouds: The Web 2.0, cloud computing, and privacy", Nw. J. Tech. \& Intell. Prop., vol. 9, 29.

LEIMEISTER, S.; BÖHM, M.; RIEDL, C. \& KRCMAR, H. (2010): "The Business Perspective of Cloud Computing: Actors, Roles and Value Networks", ECIS 2010 Proceedings.

MARSTON, S.; LI, Z.; BANDYOPADHYAY, S.; ZHANG, J. \& GHALSASI, A. (2011): "Cloud computing - The business perspective", Decision Support Systems, vol. 51: 176-189. http://dx.doi.org/10.1016/j.dss.2010.12.006 
MARTIN, T. D. (2011): "Hey! You! Get off of my cloud: defining and protecting the metes and bounds of privacy, security, and property in cloud computing", Journal of the Patent \& Trademark Office Society, vol. 92: 283-314.

MOJSILOVIC, A., RAY, B., LAWRENCE, R. \& TAKRITI, S. (2007): "A logistic regression framework for information technology outsourcing lifecycle management", Computers \& Operations Research, vol. 34: 3609-3627. http://dx.doi.org/10.1016/j.cor.2006.01.018

MURDOCH, N. (2010): "The White Choice: Should you Head into the Cloud?" Proctor 24: 24.

NICOLAOU, A. I. (2004): "Firm performance effects in relation to the implementation and use of enterprise resource planning systems", Journal of Information Systems, vol. 18: 79-105. http://dx.doi.org/10.2308/jis.2004.18.2.79

NICOLAOU, A. I. \& BHATTACHARYA, S. (2006): "Organizational performance effects of ERP systems usage: The impact of post-implementation changes", International Journal of Accounting Information Systems, vol. 7, 18-35. http://dx.doi.org/10.1016/j.accinf.2005.12.002

POPPO, L. \& LACITY, M. C. (2006): "The normative value of transaction cost economics: what managers have learned about TCE principles in the IT context". Information systems outsourcing. Springer.

POSTON, R. \& GRABSKI, S. (2000): "The impact of enterprise resource planning systems on firm performance", Proceedings of the twenty first international conference on Information systems, Association for Information Systems: 479-493.

RAGU-NATHAN, B. S.; APIGIAN, C. H.; RAGU-NATHAN, T. \& TU, Q. (2004): "A path analytic study of the effect of top management support for information systems performance", Omega, vol. 32: 459-471. http://dx.doi.org/10. /j.omega.2004.03.001

SAUNDERS, C.; GEBELT, M. \& HU, Q. (1997): "Achieving success in information systems outsourcing", California Management Review, vol. 39, 63-79

SOMA, J.; NICHOLS, M.; GATES, M. M. \& GUITERREZ, A. (2011): "Chasing the Clouds without Getting Drenched: A Call for Fair Practices in Cloud Computing Services", J. Tech. L. \& Pol'y, vol. 16: 193. 
TENG, J. T. C.; CHEON, M. J. \& GROVER, V. (2007): "Decisions to Outsource Information Systems Functions: Testing a Strategy-Theoretic Discrepancy Model", Decision Sciences, vol. 26: 75-103. http://dx.doi.org/10.1111/j.15405915.1995.tb00838.x

TIMSON, L. (2010): "Cloud' Data Center Closes Because Federal Agencies Prefer Earth". Available: http://bit.ly/aF02UB [Accessed 3/11/2012].

VASARHELYI, M. A. \& HALPER, F. B. (1991): "The continuous audit of online systems", Auditing: A Journal of Practice \& Theory, vol. 10: 110-125.

VELCU, O. (2007): "Exploring the effects of ERP systems on organizational performance: Evidence from Finnish companies", Industrial Management \& Data Systems, vol. 107: 1316-1334. http://dx.doi.org/10.1108/02635570710833983

VINCENT, M. \& HART, N. (2011): "Law in the Cloud", Law Society Journal, 51.

WANG, C.; REN, K.; LOU, W. \& LI, J. (2010): Toward publicly auditable secure cloud data storage services. Network, IEEE, vol. 24, 19-24. http://dx.doi.org/10.11 09/MNET.2010.5510914

WANG, L.; GWEBU, K. L.; WANG, J. \& ZHU, D. X. (2008): "The aftermath of information technology outsourcing: An empirical study of firm performance following outsourcing decisions", Journal of Information Systems, vol. 22: 125159. http://dx.doi.org/10.2308/jis.2008.22.1.125

WILLCOCKS, L.; FITZGERALD, G. \& FEENY, D. (1995): "Outsourcing IT: The strategic implications", Long Range Planning, vol. 28: 59-70.

WILLIAMSON, O. E. (1991): "Comparative economic organization: The analysis of discrete structural alternatives", Administrative science quarterly: 269-296.

WINTEFORD, B. (2011): "Growing pains: Amazon EC2 suffers huge outage". itNews [Online]. Available: http://bit.ly/161KQvG [Accessed 3/11/2012].

YOO, C. S. (2011): "Cloud computing: Architectural and policy implications", Review of Industrial Organization, vol. 38: 405-421.

YOUSEFF, L., BUTRICO, M. \& DA SILVA, D. (2008): "Toward a Unified Ontology of Cloud Computing", Gce: 2008 Grid Computing Environments Workshop: 42-51. 